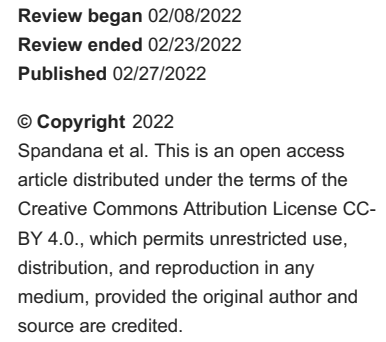

\section{An Interesting and Rare Case of Hemoglobin D- Punjab Variant in Tamil Nadu}

\author{
Rallapalli Spandana ${ }^{1}$, Karthikeyan Panneerselvam ${ }^{2}$, Sathyamoorthy Mani ${ }^{1}$, Nedunchelian \\ Krishnamoorthy ${ }^{3}$
}

1. Pediatrics, SRM Medical College Hospital and Research Centre / SRM Institute of Science and Technology, Chennai, IND 2. Pediatrics, SRM Medical College Hospital and Research Centre, Chennai, IND 3. Research, Dr. Mehta Multispeciality Hospital, Chennai, IND

Corresponding author: Karthikeyan Panneerselvam, karthikp3@srmist.edu.in

\begin{abstract}
Hemoglobin $\mathrm{D}(\mathrm{Hb} \mathrm{D})$, a variant of hemoglobin appears in a few Asian individuals belonging to India, Pakistan, Iran, Iraq, and other parts of the world. In India, it is mainly reported in the North-Western states. $\mathrm{Hb} \mathrm{D}$ disease causes subclinical jaundice, or it may be asymptomatic with pallor in its heterozygous form. Being a country with hunger and poverty, pallor is always attributed to iron deficiency anemia, but one should not miss out on various other causes.
\end{abstract}

Here, we report a rare case of $\mathrm{Hb} \mathrm{D}$ with iron deficiency anemia in a 13-year-old child of South Indian origin (Tamil Nadu) and emphasize the detailed evaluation of cases with severe pallor. He presented with gradually progressing generalized weakness with easy fatigability for the past four weeks. On examination, he was pale, there was no icterus and systemic examination was normal. Investigation revealed a microcytic hypochromic type of anemia. Hb electrophoresis showed the $\mathrm{Hb}$ D-Punjab variant. Iron indices were suggestive of iron deficiency anemia. He was advised iron supplements for three months, and he improved with that. He was counseled about his disease and was advised regular follow-up.

Categories: Pediatrics

Keywords: tamil nadu, child, hemoglobinopathy, anemia, hemoglobin d

\section{Introduction}

Hemoglobin $\mathrm{D}(\mathrm{Hb} \mathrm{D})$, a variant of hemoglobin appears in a few Asian individuals belonging to India, Pakistan, Iran, Iraq, and other parts of the world [1]. In India, it is mainly reported in the North-Western states. It has not been reported in Tamil Nadu, India. $\mathrm{Hb} \mathrm{D}$ disease causes subclinical jaundice, or it may be asymptomatic with pallor in its heterozygous form [2]. In India, the prevalence of Iron deficiency anemia in children (6-59 months) is reported as 56\% [3], most commonly due to nutritional iron deficiency. India is ranked at the 71st position in the Global Food Security Index, which was released in October 2021. In India, pallor is often associated with iron deficiency anemia, however, various other causes, such as hemoglobin D (Punjab), should not be ignored.

\section{Case Presentation}

A 13-year-old well-nourished adolescent boy from Chennai, Tamil Nadu, belonging to the lower-middle socioeconomic status (as per the Modified Kuppuswamy scale), who consumes a mixed Indian diet, presented with severe pallor, easy fatigability, and palpitations for one month. He had a history of pica.

There was no history suggestive of recurrent fever or jaundice, abdominal pain, significant weight loss, tuberculosis, and blood or worms in stools recorded in the past. This boy was a single child, born to fourthdegree consanguineous parents. There was no history of severe pallor or blood transfusion in his parents.

On examination, the child had severe pallor. He was well-oriented. Vital parameters were stable. There was no icterus, edema, lymphadenopathy, or clubbing. Cardiovascular examination showed Grade 3, short systolic murmur (hemic murmur) in the pulmonary area without any thrill. On abdominal examination, there was no organomegaly. Per rectal examination was normal. All other systemic examinations were unremarkable.

Laboratory investigations at the time of admission showed hemoglobin of $4.8 \mathrm{~g} / \mathrm{dL}$, serum (S.) iron of 14 $\mathrm{mcg} / \mathrm{dL}$, transferrin saturation of $3 \%$, total iron-binding capacity (TIBC) of $483 \mathrm{mcg} / \mathrm{dl}$, S. ferritin of 3.57 $\mathrm{ng} / \mathrm{dL}$, and peripheral smear showed microcytic hypochromic anemia. Sickling test, direct and indirect Coombs test, and stool for occult blood were all negative. Renal function tests and USG abdomen and pelvis were normal. $2 \mathrm{D}$ echocardiogram was normal.

Since there was severe pallor in a well-nourished adolescent child, the possibility of hemoglobinopathies 


\section{Cureus}

was also considered, and $\mathrm{Hb}$ electrophoresis was done as the initial work-up. Hb electrophoresis revealed $\mathrm{Hb}$ $\mathrm{F}<0.8 \%, \mathrm{Hb} \mathrm{A} 0$ of $70.3 \%, \mathrm{HbA} 2$ of $1.8 \%$, and $\mathrm{Hb} \mathrm{D}$ of $17.4 \%$.

The child was started on oral iron supplements, advised an iron-rich diet at discharge, and was asked to come for review after three months of iron supplementation. The child improved symptomatically with the disappearance of a hemic murmur heard in the pulmonary area. CBC and iron indices on admission and on follow-up revealed the following (Table 1). Peripheral smear was normal post-treatment.

\begin{tabular}{|c|c|c|}
\hline & At admission & After 5 months of follow-up treatment \\
\hline RBC & 3.49 millions/cumm & 5.42 millions/cumm \\
\hline $\mathrm{Hb}$ & $4.8 \mathrm{~g} / \mathrm{dL}$ & 13.3 g/dL \\
\hline Hematocrit & $20.8 \%$ & $43.5 \%$ \\
\hline MCV & $59.6 \mathrm{fl}$ & $80.3 \mathrm{fl}$ \\
\hline $\mathrm{MCH}$ & $14.3 \mathrm{pg}$ & $24.5 \mathrm{pg}$ \\
\hline MCHC & 24 g/dL & 30.6 g/dL \\
\hline RDVV-CV & $23.9 \%$ & $14.9 \%$ \\
\hline WBC & 9970 cells/cumm & 8410 cells/cumm \\
\hline Neutrophils & $70.8 \%$ & $69.1 \%$ \\
\hline Lymphocytes & $24.2 \%$ & $26.4 \%$ \\
\hline Eosinophils & $0.40 \%$ & $1.80 \%$ \\
\hline Monocytes & $3.60 \%$ & $2 \%$ \\
\hline Basophils & $0.50 \%$ & $0.50 \%$ \\
\hline Immature granulocytes & $0.50 \%$ & $0.20 \%$ \\
\hline $\mathrm{nRBC}$ & $0.20 \%$ & 0 \\
\hline Platelets & 4./2 lakhs/cumm & 3.0/lakhs/cumm \\
\hline
\end{tabular}

\section{TABLE 1: CBC and iron indices on admission and on follow-up}

MCHC: mean corpuscular hemoglobin concentration; MCV: mean corpuscular volume; $\mathrm{MCH}$ : mean corpuscular hemoglobin; RDW-CV: red blood cell distribution width; nRBC: nucleated red blood cells

\section{Discussion}

$\mathrm{Hb}$ D-Punjab and Hb D-Los Angeles are said to be the same as discovered first in a family of American British multiethnicity, originally of Indian origin, in which glutamine substitutes glutamic acid by position 121 of the $\beta$ globin chain [4]. Although $\mathrm{Hb} \mathrm{D}$ is not uncommon in India, its homozygous form is very rare, and very few cases have been reported in the literature [5]. Hb D shows electrophoretic mobility similar to $\mathrm{Hb} \mathrm{S}$ in alkaline $\mathrm{pH}$, whereas $\mathrm{Hb} \mathrm{D}$ movement resembles $\mathrm{Hb} \mathrm{A}$, in acidic $\mathrm{pH}$ [6-7].

A total of $1198 \mathrm{Hb}$ variants have been termed as per the September 2014 Globin Gene Server record. The majority of these $\mathrm{Hb}$ D variants do not cause clinical manifestations but some symptomatic cases can have associated hemoglobinopathies. $\mathrm{Hb} \mathrm{S}$ is the most commonly found trait in the world. Its clinical outcomes are severe when it is in homozygous form or in combination with other hemoglobinopathies like $\beta$ -

Thalassemia, $\mathrm{Hb} \mathrm{C}$, and $\mathrm{Hb} \mathrm{D}[8]$. Hb DD, the rarest form of inheritance, is usually asymptomatic but few can develop mild or moderate hemolytic anemia [9-10]. Hb D trait cases do not develop hemoglobin D disease or sickle cell disease later in life, but their traits can be passed to their next generations who can have hemoglobin D disease, hemoglobin SD disease, and hemoglobin D/ $\beta$-thalassemia disease. Hemoglobin DPunjab, together with sickle hemoglobin, causes severe health issues [11]. Red blood cells in patients with hemoglobin D disease majorly contain hemoglobin D. Excess of $\mathrm{Hb} \mathrm{D}$ can decrease the RBCs' size and numbers causing mild anemia. $\mathrm{Hb} \mathrm{D}$ disease generally does not cause serious health problems [11].

When a parent has a $\mathrm{Hb} \mathrm{D}$ trait while the other parent has a $\beta / 0$ thalassemia trait, a $25 \%$ (1 in 4 ) risk with every pregnancy is of having a kid with hemoglobin $\mathrm{D} / \beta 0$ thalassemia $(\mathrm{D} \beta 0)$ disease, which is a lifetime 
ailment causing severe health troubles [11]. Molecular studies are always recommended as final investigations but not followed in the majority of the cases.

Pandey S et al. in 2012 showed that hypochromic microcytic cell indices were reported only with clinically asymptomatic $\mathrm{Hb} \mathrm{D}$ patients for moderate anemia [2]. Dash and colleagues (1988) reported the association between $\mathrm{Hb} \mathrm{D}$ and hematological malignancies [12].

On searching for $\mathrm{Hb} \mathrm{D}$ case reports in Tamil Nadu, as well as $\mathrm{Hb} \mathrm{D}$ and iron-deficiency anemia-related case reports, were not found.

Although the gold standard test for the diagnosis of hemoglobinopathy is a molecular study, most cases are diagnosed with HPLC. A molecular study was not carried out in this index case. In our case, parents were not investigated for hemoglobinopathies.

\section{Conclusions}

Hemoglobin D-Punjab variant is a rare entity seen mostly in the North-Western part of India. But it should also be considered in patients of South India, Tamil Nadu, who are presenting as well-nourished children with severe iron deficiency anemia. This vital differential should always be kept in the mind of physicians, who deal with several alleged hemoglobinopathies.

\section{Additional Information \\ Disclosures}

Human subjects: Consent was obtained or waived by all participants in this study. Conflicts of interest: In compliance with the ICMJE uniform disclosure form, all authors declare the following: Payment/services info: All authors have declared that no financial support was received from any organization for the submitted work. Financial relationships: All authors have declared that they have no financial relationships at present or within the previous three years with any organizations that might have an interest in the submitted work. Other relationships: All authors have declared that there are no other relationships or activities that could appear to have influenced the submitted work.

\section{References}

1. Firkin F, Chesterman C, Penington D, Rush B: Disorders of hemoglobin structure and synthesis . de Gruchi's Clinical Haematology in Medical Practice. 5 ed. Blackwell Science, Oxford, United Kingdom; 1996. 137-71.

2. Pandey S, Mishra RM, Pandey S, Shah V, Saxena R: Molecular characterization of hemoglobin D Punjab traits and clinical-hematological profile of the patients. Sao Paulo Med J. 2012, 130:248-51. 10.1590/s151631802012000400008

3. Kailas L, Umair CH, Sankar VH: An untold tale of iron deficiency anemia. Indian Pediatr. 2020, 15:575-576.

4. Das R, Saxena R, Pati HP, Mahapatra M: Disorders of haemoglobin structure and synthesis . de Gruchy's Clinical Haematology in Medical Practice. 6th Ed. Blackwell Science, Oxford, United Kingdom; 2013. 120-45.

5. Jain RC: Hemoglobin D disease: report of a case . Am J Clin Pathol. 1971, 56:40-2. 10.1093/ajcp/56.1.40

6. Torres Lde S, Okumura JV, Silva DG, Bonini-Domingos CR: Hemoglobin D-Punjab: origin, distribution and laboratory diagnosis. Rev Bras Hematol Hemoter. 2015, 37:120-6. 10.1016/j.bjhh.2015.02.007

7. Itano HA: A third abnormal hemoglobin associated with hereditary hemolytic anemia . Proc Natl Acad Sci U S A. 1951, 37:775-84. 10.1073/pnas.37.12.775

8. Vella F, Lehmann H: Haemoglobin D Punjab (D Los Angeles) . J Med Genet. 1974, 11:341-8. 10.1136/jmg.11.4.341

9. Adekile A, Mullah-Ali A, Akar NA: Does elevated hemoglobin F modulate the phenotype in Hb SD-Los Angeles?. Acta Haematol. 2010, 123:135-9. 10.1159/000276998

10. Taghavi Basmanj M, Karimipoor M, Amirian A, et al.: Co-inheritance of hemoglobin D and $\beta$-thalassemia traits in three Iranian families: clinical relevance. Arch Iran Med. 2011, 14:61-3.

11. Hemoglobin D trait. What is hemoglobin? (2021). Accessed: 28-01-2022: https://www.stjude.org/treatment/disease/sickle-cell-disease/diagnosing-sickle-cell/hemoglobin-dtrait.html.

12. Dash S, Kumar S, Dash RJ: Hematological malignancy in hemoglobin D disease . Am J Hematol. 1988, 27:305. 10.1002/ajh.2830270416 